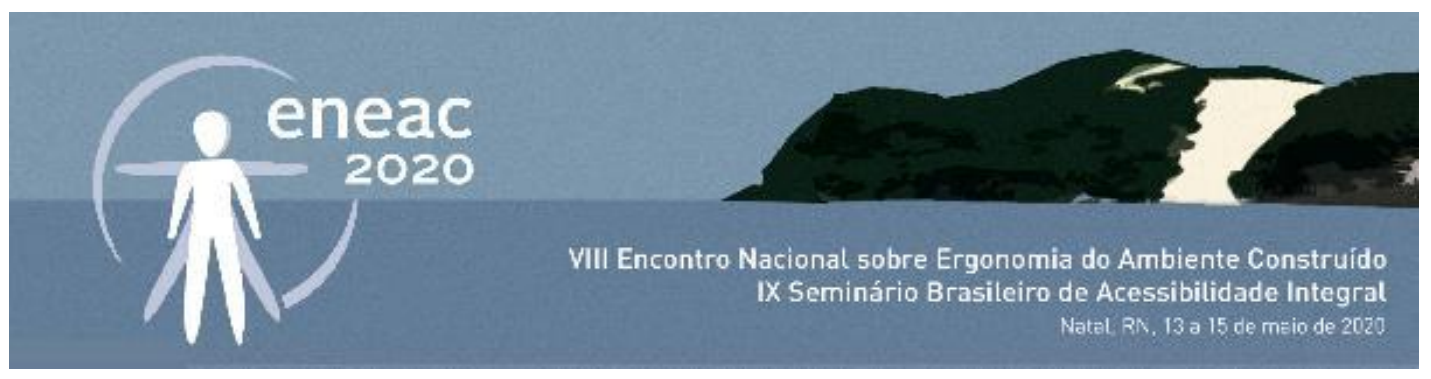

\title{
Análise Ergonômica: Estudo de Caso em uma Biblioteca Pública
}

\author{
Ergonomic Analysis: Case Study in a Public Library
}

DENIZE FABIANI

Mestra em Engenharia Civil e Ambiental (PPGENG-UPF),

PPGEP-UFRGS, denizefabiani@yahoo.com.br

MARINA BERNARDES

Mestra em Arquitetura e Urbanismo (PPGARQURB-UFSC), UNIDAVI, arq.marinabernardes@gmail.com

GRACE TIBÉRIO CARDOSO

Doutora em Ciências da Engenharia Ambiental (PPGSEA-USP), PPGARQ-IMED, grace.cardoso@imed.edu.br

\section{RESUMO}

Os conceitos de ergonomia aplicados às atividades laborais visam proporcionar melhores condições de trabalho, considerando aspectos físicos e psicológicos dos trabalhadores, para que as tarefas prescritas de cada função sejam executadas adequadamente e contribuam para uma boa produtividade. Esta pesquisa teve como objetivo identificar e analisar os principais problemas ergonômicos nas atividades laborais em uma Biblioteca Pública Municipal, e propor melhorias na qualidade dos ambientes. A pesquisa foi realizada por meio da abordagem multimétodos, sendo assim, foram utilizadas observações direcionadas à avaliação dos ambientes e comportamento dos trabalhadores, medições de parâmetro de conforto ambiental e aplicação de questionários. Os resultados evidenciaram prioridades para a melhoria dos ambientes analisados, como: o controle dos níveis de temperatura; aumento dos níveis de iluminamento; elaboração de um novo layout espacial com adequação do mobiliário e às questões relacionadas à acessibilidade.

PALAVRAS-CHAVE: Ergonomia. Atividades laborais. Abordagem multimétodos.

\section{ABSTRACT}

The concepts of ergonomics applied to labour activities aim to provide better working conditions, considering the physical and psychological aspects of workers, so that the prescribed tasks of each function are performed appropriately and Contribute to good productivity. This research aimed to identify and analyse the main ergonomic problems in labour activities at a Municipal public library, to propose improvements in the quality of the environments.The research was carried out through the multi-method approach. Thus, observations were used to evaluate the environment and behaviour of workers, measurements of environmental comfort parameter and application of questionnaires. The results showed priorities for the improvement 
of the analysed environments, such as the control of temperature levels; increased illumination levels; Elaboration of a new spatial layout with the adequacy of furniture and issues related to accessibility.

KEYWORDS: Ergonomics. Labour activities. Multi-method approach.

\section{INTRODUÇÃO}

O ambiente de trabalho e os elementos que o compõem interferem diretamente nas pessoas que nele estão inseridas. Dessa maneira, as atividades laborais são influenciadas por aspectos físicos, organizacionais, cognitivos e psicossociais, sendo que, quando um ambiente laboral responde às necessidades dos usuários, tanto em termos funcionais quanto formais, consequentemente terá um impacto positivo na realização das atividades, pois um ambiente confortável facilita o trabalho, gera maior produtividade e minimiza acidentes (SCOPEL, 2015).

As características do ambiente de trabalho incluem fatores relacionados à iluminação, ruído e níveis térmicos adequados que, inevitavelmente refletem sobre o indivíduo. Dessa forma, edificações insalubres quanto ao aspecto ambiental, podem causar uma série de desconfortos para seus ocupantes (HUANg et al., 2012). Desse modo, para que um trabalhador seja motivado e realize satisfatoriamente sua função, o ambiente deve estar adequado às necessidades da atividade laboral, uma vez que o indivíduo tende a passar maior parte do tempo de sua vida no local de trabalho (SILVA; LUCAS, 2009).

Nesse sentido, a Ergonomia busca o entendimento da interação entre o homem e seus meios, métodos e ambientes de trabalho, sendo que, seu objetivo é produzir um conjunto de conhecimentos que, quando aplicados, resultem na melhor adaptação do emprego tecnológico e dos ambientes de trabalho ao homem (IEA, 2019). Portanto, uma das premissas da Ergonomia é a humanização do trabalho, propiciando condições mais satisfatórias para um melhor desempenho e satisfação laboral, além dos demais fatores que permeiam o ambiente ocupacional, contribuindo para a melhoria da saúde, bem-estar e qualidade de vida dos mesmos (SILVA; LUCAS, 2009).

Uma das formas de avaliar a Ergonomia em ambientes de trabalho e práticas laborais é por meio da Análise Ergonômica do Trabalho (AET). De acordo com o Manual de Aplicação da Norma Regulamentadora no 17, que corresponde à Ergonomia, a AET é um processo construtivo e participativo para a solução de um problema que exige o conhecimento das tarefas, da atividade desenvolvida para realizá-las e das dificuldades enfrentadas para se atingirem o desempenho e a produtividade exigidos (MTE, 2002). Um exemplo de equipamento público que desempenha um importante papel na sociedade são as bibliotecas públicas. Ao mesmo passo que contam com inúmeros trabalhadores e recebem um público variado, são frequentemente, estabelecimentos precários. A falta de ambientes adequados às atividades e demandas laborais, locações improvisadas e acomodações impróprias acabam gerando desconforto aos trabalhadores e usuários, que por sua vez, diminuem a frequência de visitas à biblioteca (BORTOLIN et al., 2015).

Além das condições ambientais que influenciam nas atividades laborais, a função dos profissionais nas bibliotecas exige esforço físico, como o atendimento ao usuário, seja no auxílio à busca dos volumes solicitados, exigindo esforços posturais e gestuais dos membros superiores e inferiores. Na maioria das situações, as atividades também exigem atenção e concentração, podendo gerar sobrecarga mental, desgaste e ansiedade (SILVA; LUCAS, 2009). 


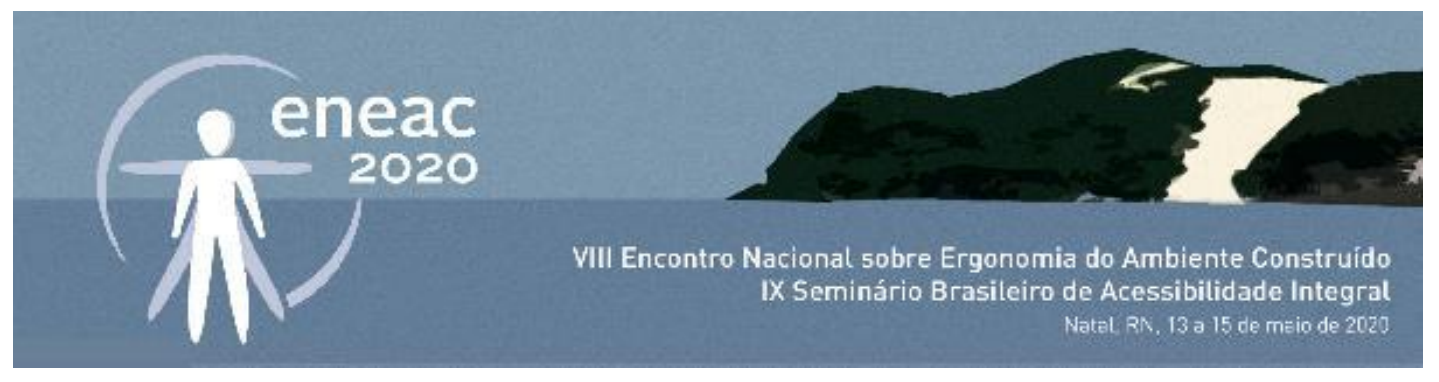

Somente o estado do Rio Grande do Sul possui um total de 523 Bibliotecas Públicas (SNBP, 2015). Assim, é evidente a relevância de estudos relacionados às melhorias ergonômicas de bibliotecas existentes, e proposição de projetos arquitetônicos para as novas edificações, com soluções apoiadas nas necessidades de seus usuários e funcionários. Diante disso, o objetivo deste artigo é apresentar a análise ergonômica de três ambientes distintos em uma biblioteca pública municipal.

\section{MÉTODOS E TÉCNICAS}

\section{Caracterização da Biblioteca}

A Biblioteca Pública Municipal, objeto dessa análise, situa-se na região central de um município ao norte do estado do Rio Grande do Sul. Foi projetada e construída exclusivamente para essa finalidade e inaugurada em 1982, tendo seu projeto arquitetônico considerado arrojado para a época com seu formato hexagonal. Após trinta anos de uso sem manutenção adequada, recebeu uma reforma em 2013. Apesar de seu espaço físico não ter sido ampliado, continuando com a área total construída de $310 \mathrm{~m}^{2}$, foram realizadas melhorias externas e internas (PMPF, 2018).

Os serviços oferecidos aos usuários são: empréstimo domiciliar, consulta local, acesso a computadores com internet, contação de histórias e demais atividades pedagógico-culturais (teatro, música e dança). Os ambientes que compõem a biblioteca compreendem a secretaria, direção, acervo adulto, acervo infantil, informática, depósito, copa e sanitários públicos. A equipe é composta por oito funcionárias, todas professoras de formação (séries iniciais e ensino fundamental) que atuam como auxiliares de biblioteca (atendentes) e diretoras de serviços culturais (coordenadoras).

A análise realizada contemplou os ambientes da secretaria, direção e acervo adulto, que também é ocupado para as atividades culturais, por serem considerados os locais com maiores problemas ergonômicos. A Figura 1 apresenta a planta baixa do layout e da configuração ambiental com a demarcação dos ambientes de análise e seus aparatos físicos (mobiliário e equipamentos principais). 
Figura Erro! Nenhuma sequência foi especificada.. Ambientes de análise da biblioteca e sua conformação física.

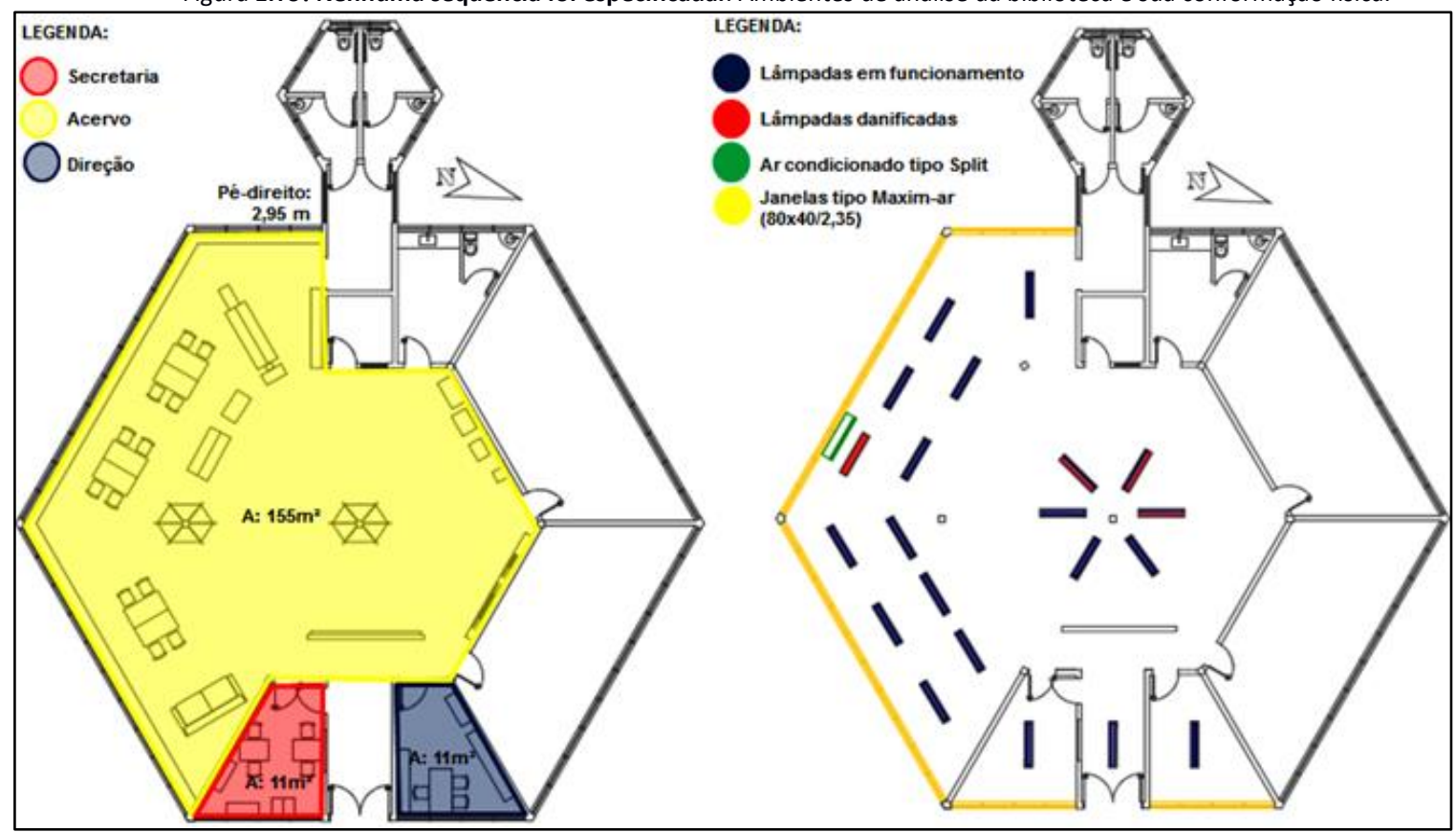

Fonte: Acervo dos Autores.

\section{Procedimentos Metodológicos}

Os procedimentos metodológicos da análise ergonômica foram realizados em três etapas: análise física e ambiental, análise da percepção dos trabalhadores e diagnóstico e recomendações, conforme apresentadas abaixo.

\section{Análise física e ambiental}

A visita exploratória contribuiu para o primeiro contato com os ambientes da biblioteca e organização das atividades e tarefas, como também, para o levantamento físico desses ambientes em se tratando de configuração ambiental e espacial. O registro das informações teve o apoio de uma ficha cadastral que possibilitou organizar e direcionar a execução do levantamento.

A observação direcionada do trabalho e dos ambientes em uso permitiu identificar os principais problemas encontrados e as consequências no desempenho da atividade laboral (atividade real). As observações ocorreram de forma sistematizada durante cinco dias úteis sequenciais e em turnos alternados, com duração de aproximadamente uma hora e meia para cada período de observação. $O$ registro dessas observações foi realizado a partir da adaptação de um roteiro elaborado por Zeisel (1984), contendo: Quem? Fazendo o quê/Atividade? Onde? e a descrição dos problemas encontrados no ambiente.

A medição ambiental para temperatura, umidade, iluminação e ruído da biblioteca possibilitou comparar os resultados aferidos às recomendações das normas técnicas vigentes. Para cada ambiente foram estabelecidos pontos para a medição (a depender das dimensões físicas e dos procedimentos indicados em cada norma utilizada) e apresentados em planta baixa, sendo que, todos os pontos foram medidos nos períodos da manhã e tarde a fim de contemplar 


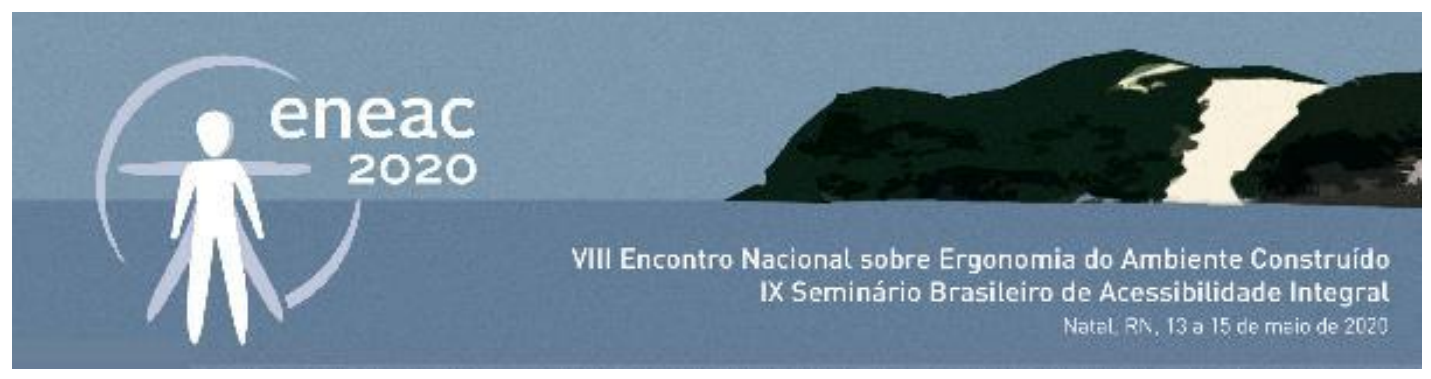

uniformemente a jornada de trabalho de todas as profissionais da biblioteca. Para tanto, as condições climáticas do dia em que se realizaram as medições foram descritas permitindo melhor compreensão e análise dos dados levantados.

Para medir o conforto térmico (temperatura e umidade) foi utilizado o Termo-Higrômetro Portátil, marca Akso, modelo AK630. Os resultados foram comparados à NR 17, que recomenda temperatura entre $20{ }^{\circ} \mathrm{C}$ e $23{ }^{\circ} \mathrm{C}$ e umidade não inferior a $40 \%$. A leitura do instrumento foi efetuada no local onde permanece o trabalhador (Brasil, 2018). Para medir o conforto lumínico foi utilizado o Luxímetro Digital, marca Akso, modelo AK310. Os resultados foram comparados à NHO 11, que recomenda uma iluminância de 500 lux para a área de leitura e para o ambiente de atendimento pelos bibliotecários. A leitura do instrumento foi efetuada no plano da tarefa visual quando definido (no caso de mesas de trabalho) ou em um plano horizontal a uma altura de $0,75 \mathrm{~m}$ do piso (Fundacentro, 2018).

Para medir o conforto acústico foi utilizado o Decibelímetro Digital, marca Akso, modelo AK820. O equipamento operou no circuito de compensação " $A$ " e circuito de resposta lenta "SLOW". Os resultados foram comparados a ABNT NBR 10152, que recomenda para bibliotecas níveis de pressão sonora entre 35 e $45 \mathrm{~dB}(\mathrm{~A})$. A leitura do instrumento foi efetuada próxima à altura do trabalhador (ABNT, 2017).

\section{Análise da percepção dos trabalhadores}

Realizou-se uma entrevista semiestruturada com questões abertas direcionadas à coordenadora geral da biblioteca. As perguntas tinham por objetivo conhecer o funcionamento da biblioteca, as funções e atividades dos trabalhadores, como também, compreender os problemas ergonômicos percebidos por eles no seu ambiente de trabalho e atividade laboral.

A aplicação do questionário foi realizada em um dia (manhã e tarde), sendo que, as participantes foram informadas sobre os objetivos da pesquisa e orientadas a assinar o Termo de Consentimento Livre e Esclarecido (TCLE). Por meio do questionário foi permitido avaliar as percepções dos trabalhadores quanto ao seu ambiente de trabalho, e sua estrutura contemplou os fatores sociais, ambientais e projetuais. Os fatores sociais referem-se aos aspectos pessoais e relacionados ao trabalho. Os fatores ambientais correspondem às condições térmicas, acústicas e lumínicas. Os fatores de projeto são relativos aos aspectos físicos e funcionais como dimensionamento, layout e estética. O questionário utilizado, composto por vinte e uma perguntas, seguiu a classificação adaptada de Baker et al. (1994) e ISO 10551 (ISO, 2011). Para cada questão, os respondentes poderiam escolher em uma escala Likert de cinco pontos, a sua percepção com relação a determinado ambiente (Totalmente desconfortável, Quase sempre desconfortável, Indiferente, Confortável e Bastante confortável - para as questões relacionadas aos fatores ambientais) e (Péssimo, Ruim, Regular, Bom e Ótimo - para as questões relacionadas aos fatores projetuais). 


\section{DISCUSSÃO E RESULTADOS}

\section{Levantamento físico}

O levantamento físico permitiu verificar o esquema geral de materiais e cores predominantes nos ambientes, como também, o esquema geral dos elementos que compõem a iluminação, a ventilação e os equipamentos existentes, como mostra Tabela 2.

Tabela 2. Levantamento físico da biblioteca.

\begin{tabular}{|c|c|c|c|}
\hline \multicolumn{4}{|c|}{ ESQUEMA GERAL - MATERIAIS E CORES PREDOMINANTES } \\
\hline A VERIFICAR & \multicolumn{2}{|c|}{ MATERIAIS } & CORES \\
\hline Paredes & \multicolumn{2}{|c|}{ Alvenaria } & Branco \\
\hline Piso & \multicolumn{2}{|c|}{ Porcelanato } & Branco \\
\hline Teto & \multicolumn{2}{|c|}{ Laje } & Branco \\
\hline Janelas & \multicolumn{2}{|c|}{ Esquadria metálica } & Branco \\
\hline Portas & \multicolumn{2}{|c|}{ Madeira } & Branco \\
\hline Mobiliário & \multicolumn{2}{|c|}{ Madeira } & Marrom \\
\hline \multicolumn{4}{|l|}{ ESQUEMA GERAL - ILUMINAÇÃO } \\
\hline Tipo de iluminação & \multicolumn{3}{|c|}{ Natural e artificial } \\
\hline Tipo de luminária & \multicolumn{3}{|c|}{ Sobrepor simples, tipo trapézio com duas lâmpadas } \\
\hline Tipo de lâmpada & \multicolumn{3}{|c|}{ Lâmpada tubular fluorescente $40 \mathrm{~W}$} \\
\hline \multirow{2}{*}{$\begin{array}{c}\text { Quantidade de } \\
\text { luminária/lâmpada }\end{array}$} & Acervo & Secretaria & Direção \\
\hline & $\begin{array}{l}17 \text { luminárias } \\
34 \text { lâmpadas }\end{array}$ & $\begin{array}{l}1 \text { luminária } \\
2 \text { lâmpadas }\end{array}$ & $\begin{array}{l}1 \text { luminária } \\
2 \text { lâmpadas }\end{array}$ \\
\hline \multirow{2}{*}{ Orientação solar das janelas } & Acervo & Secretaria & Direção \\
\hline & Leste e Sul & Leste & Leste \\
\hline \multicolumn{4}{|c|}{ ESQUEMA GERAL - VENTILAÇÃO } \\
\hline Tipo de ventilação & \multicolumn{3}{|c|}{ Natural e artificial } \\
\hline $\begin{array}{l}\text { Tipo e Quantidade } \\
\text { Ar condicionado }\end{array}$ & \multicolumn{3}{|c|}{1 Ar condicionado tipo Split 30.000 BTUs - no Acervo } \\
\hline \multicolumn{4}{|c|}{ ESQUEMA GERAL - EQUIPAMENTOS } \\
\hline Equipamentos & \multicolumn{3}{|c|}{$\begin{array}{l}2 \text { Computadores de mesa; } 1 \text { impressora; } 1 \text { base de telefone sem fio - todos na } \\
\text { Secretaria }\end{array}$} \\
\hline
\end{tabular}

Ao analisar a biblioteca internamente, observou-se que, paredes, piso e teto possuem cores brancas, que contribuem para maior claridade dos ambientes, pois reflete melhor a luz. A iluminação natural proveniente das janelas de maneira indireta por possuir elevado peitoril e, portanto, encontrando-se acima do nível do observador, também auxilia na claridade do ambiente, além de não incidir diretamente nas estantes do acervo. A biblioteca não possui isolamento acústico, pois as janelas não dispõem de um sistema de vedação adequado, o que aumenta o ruído proveniente de fontes externas. Além disso, a porta de acesso permanece aberta durante o horário de funcionamento da biblioteca, não fornecendo auxílio no isolamento acústico e térmico. O piso porcelanato da biblioteca é considerado adequado, corroborando as afirmações de Trinkley (2001) quanto a sua resistência à água, ao fogo e à proliferação de fungos e insetos, como também, à facilidade de manutenção e qualidade estética.

O mobiliário da biblioteca não é considerado adequado, apresentando-se de forma improvisada e não atendendo requisitos mínimos de conforto ergonômico, pois as extremidades das mesas possuem quinas e as cadeiras não apresentam suporte lombar móvel, nem braços e altura 


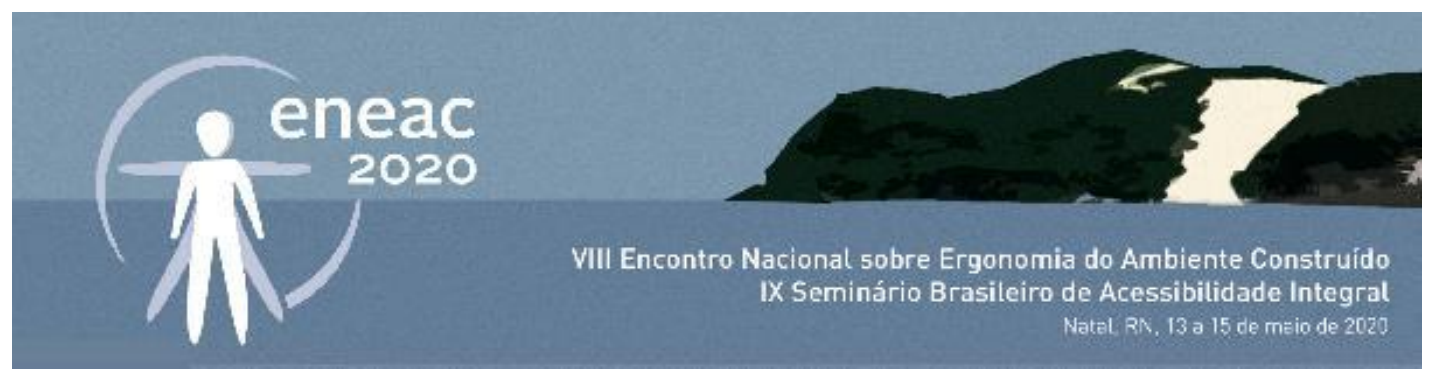

reguláveis como determina a NR 17 (Brasil, 2018). Os móveis não possuem a resistência e durabilidade adequadas, pois são de madeira, colaborando para o aparecimento de mofo e cupins. De acordo com Minuzzo (2004), os móveis adequados para uma biblioteca devem ser de aço, pois, além da resistência, evitam umidade e possível infestação de insetos, sendo que, é considerado ideal para o armazenamento do acervo o emprego de estantes de metal.

\section{Observação direcionada do ambiente em uso}

A observação direcionada apontou os principais problemas nos ambientes de trabalho analisados em consonância às atividades laborais exercidas. Os três ambientes apresentaram inúmeros problemas ergonômicos evidenciando a desconformidade com a NR 17 (Brasil, 2018). $\mathrm{Na}$ secretaria foi verificado o maior número de irregularidades, principalmente quanto ao mobiliário.

A secretaria possui dimensões (área total) incompatíveis com as atividades e usuários, sendo ainda mais prejudicada pela existência de duas portas de acesso, além de permitir a entrada de ruído externo, quando abertas. Além disso, há iluminação e ventilação deficientes e a fiação encontra-se exposta. As mesas possuem dimensões inferiores às necessidades de trabalho e de conforto. Sob as mesas há acoplado um apoio retrátil para o teclado do computador, o que desfavorece a mobilidade dos membros inferiores durante os longos períodos sentados, além de não disporem de apoio para os pés. As cadeiras são desconfortáveis, sem estofamento, regulagem de altura, e sem possibilidades de deslocamento (sistema de rodízio).

O balcão de atendimento ao público (janela sem fechamento) possui peitoril alto $(1,15 \mathrm{~m}) \mathrm{em}$ relação à mesa da atendente $(0,77 \mathrm{~m})$, além de se encontrar perpendicular em relação ao atendimento, o que necessita elevação dos braços e torção do tronco por parte da trabalhadora. A passagem entre as duas mesas existentes para atendimento é estreita, o que gera conflito espacial. Esse conflito é agravado pela má distribuição dos armários no ambiente, o que dificulta a circulação para manusear os equipamentos (impressora, telefone, estantes).

Com relação aos equipamentos, a impressora está alocada em uma altura inadequada, necessitando levantamento desconfortável dos membros superiores para o seu manuseio. Os monitores dos computadores também se encontram a uma altura inadequada em relação à distância olho-tela, gerando desconforto. Além dos armários e equipamentos, uma mesa de apoio para acomodar os livros recebidos encontra-se em local inapropriado, atrás da mesa da atendente, solicitando constante torção de tronco. A Figura 2 apresenta alguns dos problemas descritos. 
Figura 2. Ambiente - Secretaria: problemas identificados.

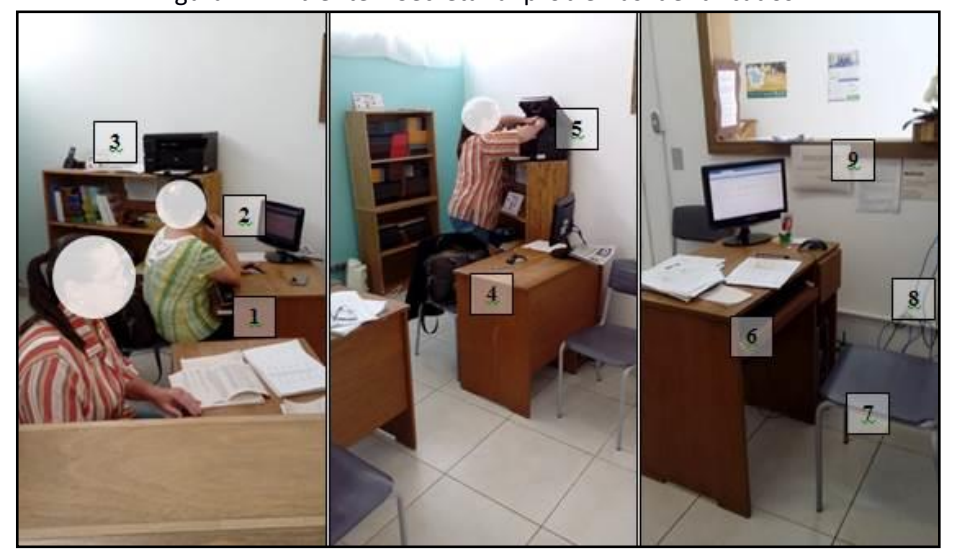

- Passagem estreita entre as mesas - conflito nos fluxos espaciais.

2- Distância olho-tela - altura insuficiente do monitor gera desconforto visual.

3- Base do telefone e impressora distantes - necessidade de movimentação e deslocamentos.

4- Mesas com quinas e dimensões insuficientes - desconforto laboral.

5- Impressora em altura inadequada - frequente elevação dos membros superiores.

6- Apoio retrátil para teclado - falta de mobilidade e conforto para os membros inferiores.

7- Cadeiras inapropriadas - sem regulagem de altura, braços e encosto.

8- Fiação exposta - risco de enroscamento/queda e choque elétrico.

9- Altura do balcão de atendimento inapropriada - elevação dos membros superiores e torção de tronco.

Fonte: Acervo dos Autores.

$\mathrm{Na}$ área de Acervo adulto foram identificados diversos problemas relacionados às estantes, sendo que se encontram rente ao chão, necessitando abaixar completamente o corpo, o que torna o manuseio dos livros, tanto por parte das trabalhadoras, quanto dos usuários, desconfortável. Além disso, com a limpeza do chão, os livros localizados na parte mais baixa ficam empoeirados, o que, associado ao material inadequado das estantes (madeira), pode trazer danos às obras e à saúde das funcionárias. Algumas estantes apresentam prateleiras com altura insuficiente para a guarda vertical dos livros, o que prejudica a visualização e organização dos volumes. Também, as estantes apresentam alturas variadas, promovendo maior ou menor elevação dos membros superiores.

O ambiente de acervo apresenta ocupação espacial em desequilíbrio, ou seja, excesso de mobiliário (estantes e mesas) e fluxos de um lado, enquanto o outro permanece uma área ociosa (destinada às atividades culturais quando necessário). Essa constatação pode ser um fator que justifique a falta de prateleiras para organizar os livros de uso local, exigido para cada volume existente em uma biblioteca pública. Uma melhor organização espacial também tornaria o ambiente mais dinâmico e funcional, uma vez que há passagens estreitas entre algumas estantes e entre estantes e mesas.

No acervo há três mesas para uso local, cada uma formando um conjunto através da união de duas mesas, com quatro cadeiras para cada conjunto. Foi constatada a falta de cabines para estudo individual e sala isolada para estudo em grupo, gerando conflito com as atividades culturais que acontecem no mesmo local, como questões relacionadas a espaço físico, ruído advindo das atividades e fluxo excessivo de usuários.

Também, foi verificado o desconforto das cadeiras, a insuficiente iluminação e ventilação, devido à incompatibilidade do ar condicionado diante às dimensões do ambiente, e excesso de 


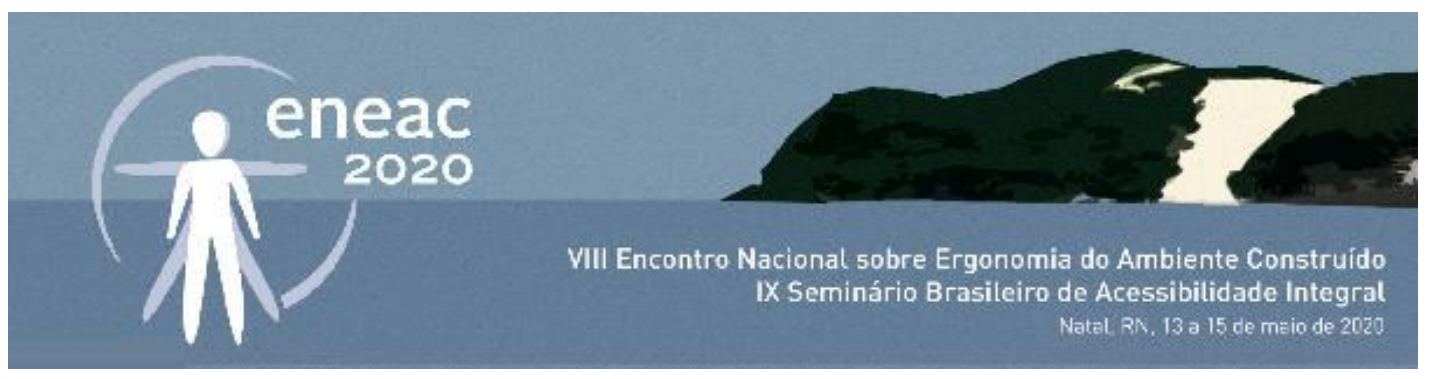

ruído externo, principalmente proveniente da via próxima, agravada pela necessidade das portas de acesso abertas. A Figura 3 mostra alguns dos problemas identificados.

Figura 3. Ambiente - Acervo adulto: problemas identificados.

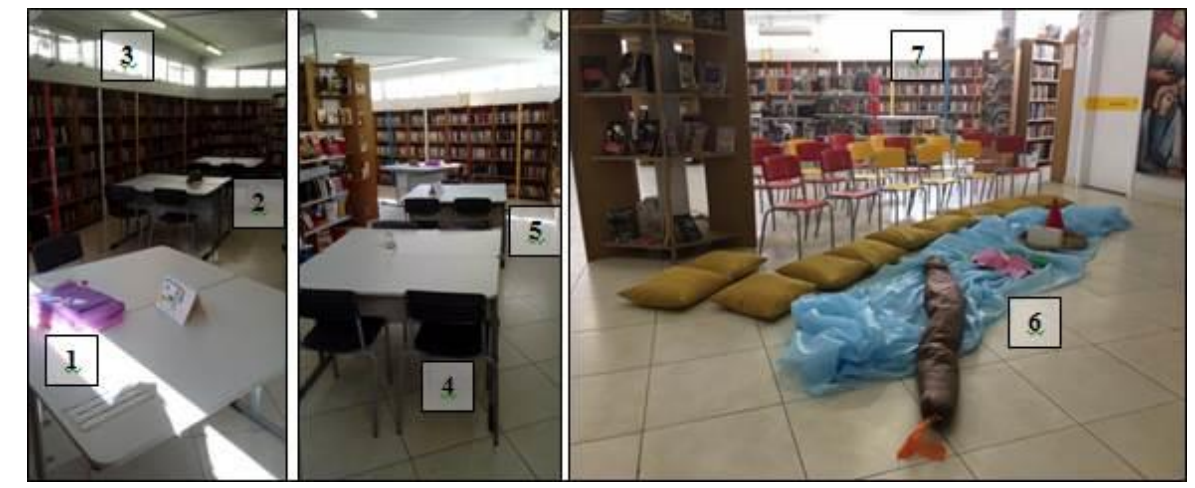

1- Mesa da atendente - estrutura e local inapropriados para posto de trabalho.

2- Mesas e cadeiras insuficientes para os usuários.

3- Iluminação e ventilação insuficientes - capacidade da unidade condicionadora de ar incompatível com as dimensões do local.

4- Cadeira inapropriada para a atendente do acervo - sem regulagem de altura, braços e encosto.

5- Estantes rentes ao chão - desconforto no manuseio dos livros e acúmulo de poeira.

6- Área geralmente ociosa - destinada às atividades culturais. Quando utilizada, gera conflitos espaciais, ruído e excesso de fluxos.

7- Mobiliário (estantes e mesas) - excesso em um único lado do acervo.

Fonte: Acervo dos Autores.

O ambiente da Direção apresenta diversos problemas espaciais, principalmente em relação às dimensões físicas incompatíveis e inadequadas para todas as atividades realizadas no local, como reuniões, elaboração de projetos, trabalhos manuais para as atividades culturais, entre outros. O problema é agravado pelo conflito no fluxo espacial devido à precária dimensão da sala associada à má distribuição do mobiliário (armários, estantes e cadeiras), gerando passagens estreitas.

Na sala há apenas uma mesa com caráter e dimensões inadequados para as atividades do local, sendo alocada de maneira improvisada. Além disso, a mesa possui quinas, assim como as cadeiras, também consideradas inapropriadas para as funções do ambiente, não possuindo regulagem de altura, braços, encosto, e sem estofamento. Esta sala também é utilizada como depósito de materiais e objetos utilizados nas atividades culturais. Devido a isso, a ventilação inadequada agrava o cheiro de mofo no ambiente. A iluminação é considerada insuficiente e não há extensão de telefone, sendo necessários constantes deslocamentos por parte das funcionárias. A Figura 4 apresenta alguns dos problemas apontados. 
Figura 4. Ambiente - Direção: problemas identificados.

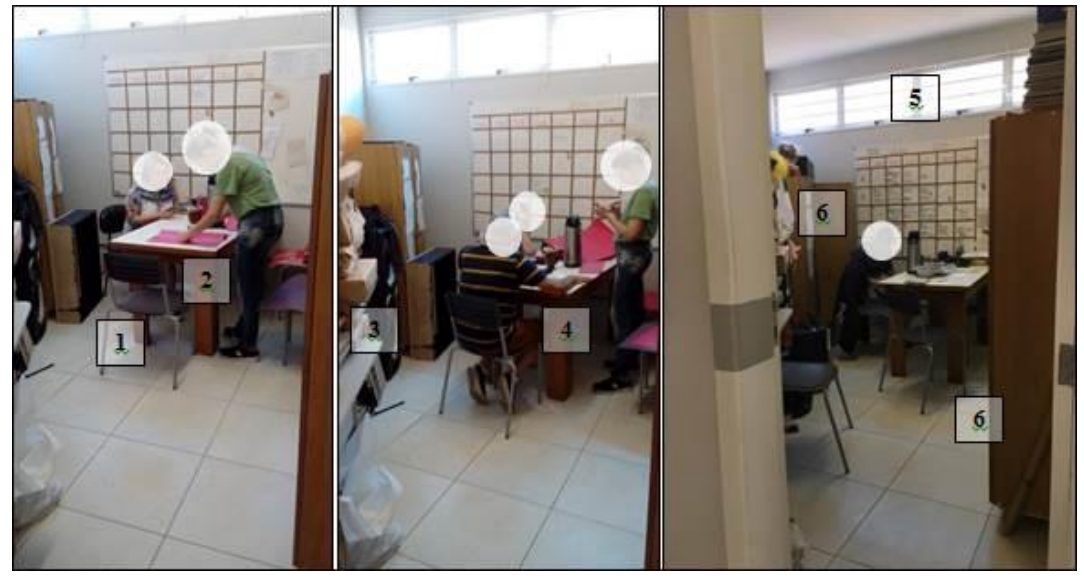

1- Cadeiras inapropriadas - sem regulagem de altura, braços e encosto.

2- Mesa improvisada, inapropriada para as atividades e com quinas - excesso de desconforto.

3- Local utilizado para depósito de materiais - gera acúmulo de objetos, conflito espacial e cheiro de mofo.

4- Espaço insuficiente para as atividades necessárias - desconforto e conflito espacial em reuniões e demais atividades.

5- Ventilação e iluminação insuficientes - desconforto geral agravando o cheiro de mofo.

6- Má distribuição do mobiliário - gera conflitos espaciais, desorganização e passagens estreitas.

Fonte: Acervo dos Autores.

\section{Medição ambiental}

A avaliação do conforto ambiental foi realizada através da medição da temperatura, umidade, iluminação e ruído para poder comparar com as exigências normativas e verificar a adequabilidade dos ambientes analisados. A tabela 3 apresenta os dados climáticos do dia da medição e a Figura 5 apresenta a planta baixa da biblioteca com a indicação dos pontos medidos, com legenda específica identificada e numerada para cada ponto aferido.

Tabela 3. Dados climáticos e identificação dos pontos de medição.

\begin{tabular}{|c|c|c|}
\hline \multicolumn{3}{|c|}{ MEDIÇÃO AMBIENTAL } \\
\hline Biblioteca Pública Municipal & Data: $18 / 12 / 2018$ & $\begin{array}{l}\text { Horários: } \\
\text { Entre 9h30min e 10h30min (Manhã) } \\
\text { Entre 14h30min e 15h30min (Tarde) }\end{array}$ \\
\hline \multicolumn{3}{|c|}{ Dados Climáticos: Cidade ao Norte do RS (para a referida data) } \\
\hline $\begin{array}{l}\text { Temperatura Mínima: } 21 \text { 으 } \\
\text { Temperatura Máxima: } 28 \circ \mathrm{C}\end{array}$ & & $\begin{array}{l}\text { dade Mínima: } 50 \% \\
\text { lade Máxima: } 90 \%\end{array}$ \\
\hline $\begin{array}{l}\text { Nascer do Sol: } 5 \mathrm{~h} 28 \mathrm{~min} \\
\text { Pôr do Sol: } 19 \mathrm{~h} 24 \mathrm{~min}\end{array}$ & Dire & $\begin{array}{l}\text { Fracos/Moderados } \\
\text { Vento: Sudoeste/Sudeste }\end{array}$ \\
\hline
\end{tabular}

Fonte: Instituto Nacional de Meteorologia (2018). Adaptado pelos Autores. 


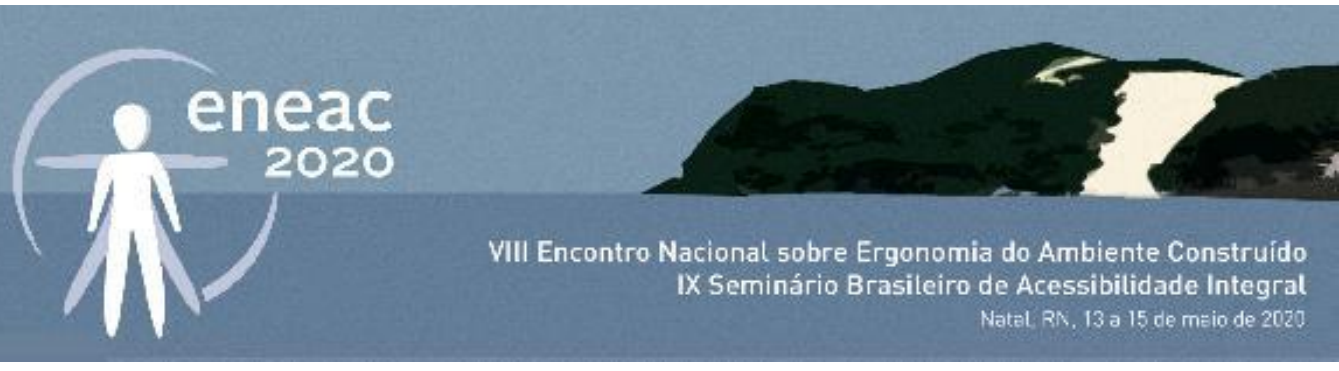

Figura 5. Planta baixa com a indicação dos pontos medidos.

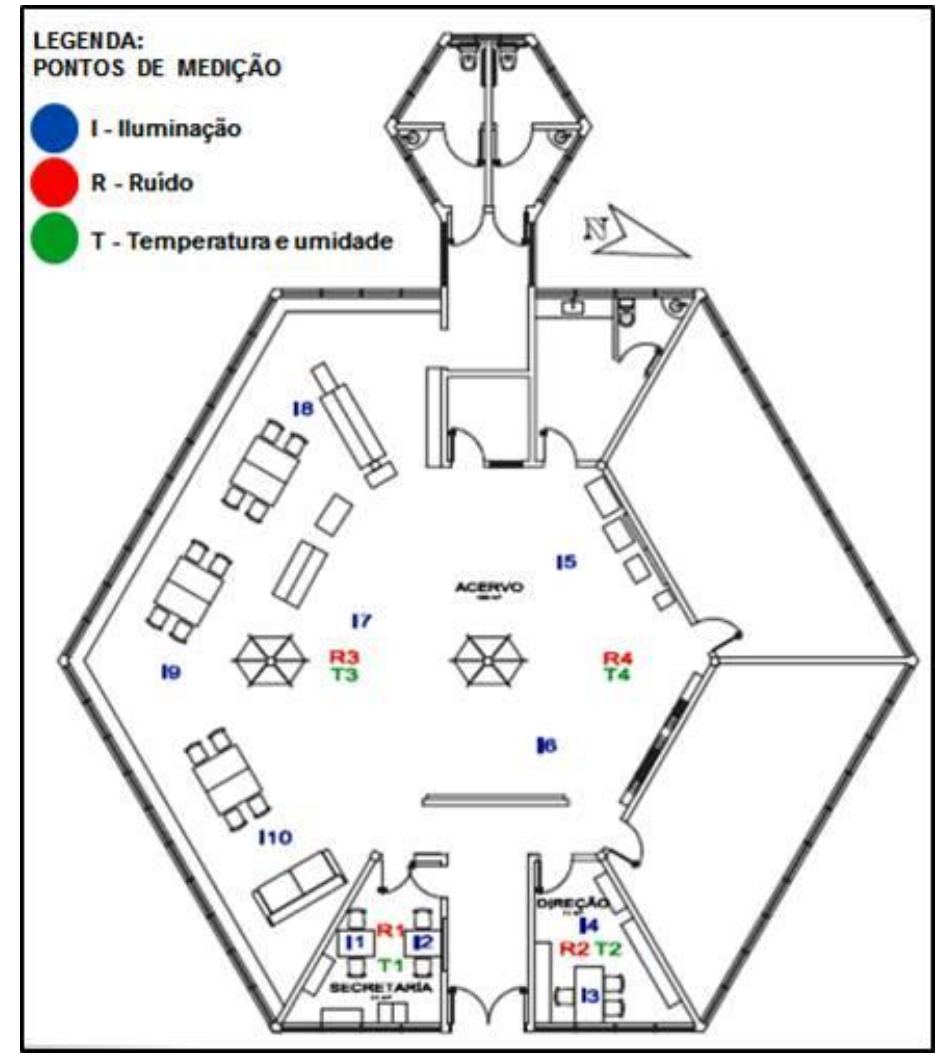

Fonte: Acervo dos Autores.

O conforto lumínico é considerado indispensável na oferta de um ambiente confortável e seguro (Miguel, 2014). Para garantir um ambiente de trabalho com iluminação adequada, deve-se aproveitar o máximo possível a luz natural, pois as pessoas são programadas para trabalhar de acordo com a luz do dia. A saúde física e mental e o desempenho dos trabalhadores são afetados quando os níveis de iluminação não estão adequados para o espaço (Scopel, 2015).

Quanto ao conforto lumínico, a Tabela 4 apresenta os resultados das medições dos níveis de iluminância dos pontos estabelecidos nas diferentes áreas dos ambientes analisados.

Tabela 4. Resultados das medições da iluminância nos pontos da biblioteca.

\begin{tabular}{c|c|c|c}
\hline \multirow{2}{*}{ PONTOS } & MEDIÇÕES ILUMINAÇÃO (lux) & \multirow{2}{*}{$\begin{array}{c}\text { RECOMENDAÇÃO } \\
\text { NHO 11 }\end{array}$} \\
\cline { 2 - 3 } & MANHÃ & TARDE & \\
\hline \multicolumn{3}{c}{ SECRETARIA } \\
\hline I1 & 945 lux & 268 lux & 500 lux \\
\hline
\end{tabular}




\begin{tabular}{c|c|c|c}
\hline & & & \\
\hline 12 & 1.130 lux & 302 lux & 500 lux \\
\hline 13 & 263 lux & 172 lux & 500 lux \\
\hline 14 & 243 lux & 170 lux & 500 lux \\
\hline 15 & DIREÇÃO & 500 lux \\
\hline 16 & 146 lux & 121 lux & 500 lux \\
\hline 17 & 255 lux & 154 lux & 500 lux \\
\hline 18 & 306 lux & 214 lux & 500 lux \\
\hline 19 & 859 lux & 577 lux & 500 lux \\
\hline 110 & 767 lux & 743 lux & 500 lux \\
\hline
\end{tabular}

Fonte: Acervo dos Autores.

A partir dos dados apresentados observou-se que a Secretaria possui níveis de iluminamento satisfatórios durante a manhã e abaixo do recomendado à tarde. Isso se deve pela posição solar em que o ambiente se encontra (Leste), bem como, pelo recebimento do iluminamento do hall de entrada e das duas portas de acesso abertas. A Direção encontra-se com o nível de iluminamento muito abaixo do recomendado em ambos os períodos aferidos. Já o Acervo, em contrapartida, possui níveis de iluminamento abaixo do recomendado nos pontos afastados das janelas (15, 16 e 17) e em conformidade nos pontos mais próximos ao recebimento de luz natural $(18,19$ e 110$)$. Esse resultado também se deve à quantidade expressiva de lâmpadas danificadas $e$ da posição solar do ambiente que, além de receber a insolação Leste, recebe parte da insolação Sul.

Outro fator que pode ter influenciado nos níveis de iluminamento dos ambientes analisados, relaciona-se à condição climática no dia da medição, em que se observou a manhã ensolarada e a tarde encoberta. Da mesma forma que o conforto lumínico, o conforto acústico é uma condição importante para alcançar o bem-estar. A ausência de conforto acústico condiciona fortemente a saúde e a produtividade do ser humano. Condições acústicas desfavoráveis acarretam alguns problemas, como dificuldade de comunicação, irritabilidade e efeitos nocivos à audição. Portanto, o ruído estressante causa irritação, agrava o mau humor, afeta a percepção visual e diminui a capacidade de aprendizado (Scopel, 2015).

Quanto ao conforto acústico, a Tabela 5 apresenta os resultados das medições dos níveis de ruído dos pontos estabelecidos nos ambientes analisados.

Tabela 5. Resultados das medições do ruído nos pontos da biblioteca.

\begin{tabular}{l|c|c|c}
\hline \multirow{2}{*}{ PONTOS } & \multicolumn{2}{|c|}{ MEDIÇÕES RUÍDO dB(A) } & \multirow{2}{*}{ RECOMENDAÇÃO } \\
& MANHÃ & TARDE 10152 \\
\cline { 2 - 3 } \\
\hline
\end{tabular}




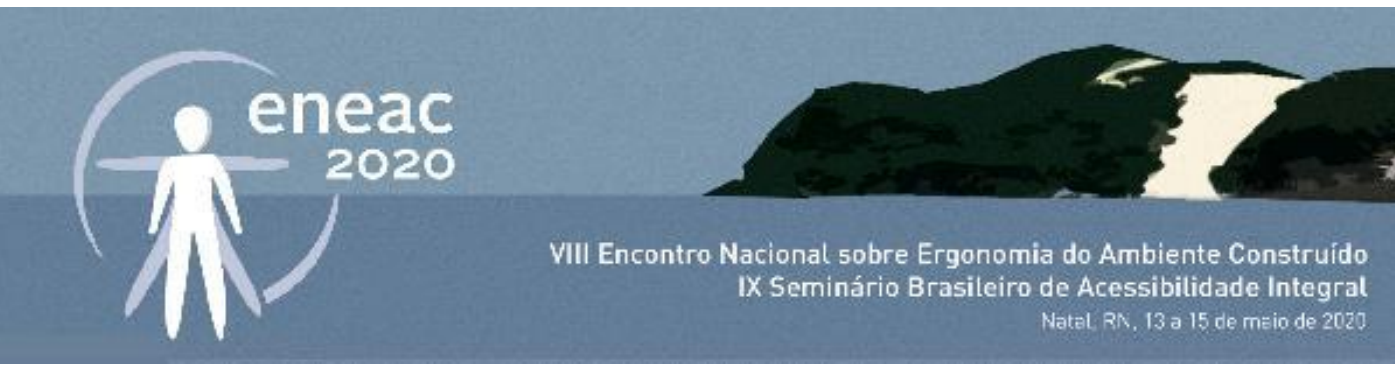

\begin{tabular}{|c|c|c|c|}
\hline R1 & $58 \mathrm{~dB}(\mathrm{~A})$ & $51 \mathrm{~dB}(\mathrm{~A})$ & $35-45 \mathrm{~dB}(\mathrm{~A})$ \\
\hline \multicolumn{4}{|c|}{ DIREÇÃO } \\
\hline $\mathbf{R} 2$ & $55 \mathrm{~dB}(\mathrm{~A})$ & $44 \mathrm{~dB}(\mathrm{~A})$ & $35-45 \mathrm{~dB}(\mathrm{~A})$ \\
\hline \multicolumn{4}{|c|}{ ACERVO } \\
\hline R3 & $67 \mathrm{~dB}(\mathrm{~A})$ & $54 \mathrm{~dB}(\mathrm{~A})$ & $35-45 \mathrm{~dB}(\mathrm{~A})$ \\
\hline R4 & $52 \mathrm{~dB}(\mathrm{~A})$ & $52 \mathrm{~dB}(\mathrm{~A})$ & $35-45 \mathrm{~dB}(\mathrm{~A})$ \\
\hline
\end{tabular}

Para os três ambientes analisados o ruído medido encontra-se acima dos índices indicados. $\mathrm{Na}$ Secretaria o nível de ruído no período da manhã é superior ao nível medido à tarde, o que pode ser explicado por haver mais trabalhadoras no período da manhã, como também, pelo ambiente permanecer constantemente aberto através da janela-balcão de atendimento, além das portas de acesso. A Direção possui os menores níveis de ruído por estar mais afastada da via de acesso com fluxo moderado, bem como por se encontrar permanentemente com as portas fechadas. Já o Acervo possui maiores níveis no ponto próximo à via (R3) e menores no ponto mais afastado (R4). Outro fator que contribuiu para o nível de ruído mais expressivo se encontrar no ponto R3 é a localização do acervo (estantes) e mesas (apoio/estudo), e por isso, ter maior fluxo de pessoas. Além disso, no dia da aferição não havia atividades culturais no local, o que contribuiu para índices, ainda que acima do recomendado, menores principalmente no período da tarde.

Assim como o conforto lumínico e acústico, o conforto térmico é fundamental, considerando que, o ambiente de biblioteca deve ter a temperatura e a umidade do ar controladas, pois o calor pode danificar os materiais e a umidade pode facilitar a proliferação de fungos, além de trazer riscos à saúde do trabalhadores e demais usuários. Ainda, uma boa ventilação é fundamental, pois gera bem-estar aos usuários, trabalhadores, como também, auxilia na conservação do acervo. Para tanto, o ar deve ser constantemente renovado por sistemas de ventilação através de filtros de alta qualidade e através de janelas dimensionadas e posicionadas adequadamente, sem corrente de ar direta, mas proporcionando a devida circulação do ar (Mello \& Santos, 2004). Quanto ao conforto térmico, a Tabela 6 apresenta os resultados das medições dos níveis térmicos e de umidade dos pontos nos ambientes da biblioteca.

Tabela 6. Resultados das medições da temperatura e umidade nos pontos da biblioteca.

\begin{tabular}{|c|c|c|c|c|c|}
\hline \multirow{3}{*}{ PONTOS } & \multicolumn{4}{|c|}{ MEDIÇÕES TEMPERATURA (ํ) / UMIDADE (\%) } & \multirow{3}{*}{$\begin{array}{c}\text { RECOMENDAÇÃO } \\
\text { NR } 17\end{array}$} \\
\hline & \multicolumn{2}{|c|}{ MANHÃ } & \multicolumn{2}{|c|}{ TARDE } & \\
\hline & TEMP. & UMIDADE & TEMP. & UMIDADE & \\
\hline
\end{tabular}




\begin{tabular}{|c|c|c|c|c|c|}
\hline \multicolumn{6}{|c|}{ SECRETARIA } \\
\hline T1 & $27,5 \stackrel{\circ}{ } \mathrm{C}$ & $54,5 \%$ & $27 \stackrel{\circ}{C}$ & $61,5 \%$ & $20-23 \stackrel{\circ}{\circ} \mathrm{C} />40 \%$ \\
\hline \multicolumn{6}{|c|}{ DIREÇÃO } \\
\hline T2 & $27,3 \circ C$ & $54,1 \%$ & $26,7 \circ C$ & $60,3 \%$ & $20-23 \circ \mathrm{C} />40 \%$ \\
\hline \multicolumn{6}{|c|}{ ACERVO } \\
\hline T3 & $25,2 \stackrel{\circ}{ } \mathrm{C}$ & $53,3 \%$ & $24,8 \stackrel{\circ}{\circ}$ & $56,2 \%$ & $20-23 \stackrel{\circ}{\circ} \mathrm{C} />40 \%$ \\
\hline T4 & $26,5 \stackrel{\circ}{ } \mathrm{C}$ & $53,8 \%$ & $26 \stackrel{\circ}{C}$ & $56,6 \%$ & $20-23 \stackrel{\circ}{\circ} />40 \%$ \\
\hline
\end{tabular}

Assim como os níveis de ruído, os três ambientes apresentaram temperaturas acima das recomendações técnicas. Analisando os três ambientes, todos registraram temperaturas um pouco maiores no período da manhã, devido principalmente à orientação solar das fachadas Leste (Secretaria e Direção) e Sudeste-Sul (Acervo), que no dia das medições contou com boas condições climáticas, com manhã de céu claro sem presença de nuvens. Os dois pontos de medição no Acervo apresentaram variações expressivas nas temperaturas. O ponto T3 em comparação ao T4 possui menores temperaturas em ambos os períodos, em função da proximidade com o ar condicionado, que no dia da aferição encontrava-se em funcionamento.

A umidade medida em todos os ambientes apresentou-se em conformidade com a normativa, que indica mais de $40 \%$. Ainda, em todos os pontos medidos os índices de umidade se mostraram maiores no período da tarde, em função do céu encoberto e das chuvas isoladas durante o período. Com os resultados demonstrados percebeu-se que, as variáveis ambientais (iluminação, ruído, temperatura) aferidas nos ambientes da biblioteca estão, em sua maioria, em desconformidade com as exigências das normas técnicas vigentes, o que compromete o conforto ambiental para as profissionais em seu ambiente e atividade laboral.

\section{Análise da percepção}

A biblioteca é composta por uma equipe de profissionais do ensino que atuam através de outras funções. Ao total, são oito funcionárias, três atendentes na Secretaria, três atendentes no Acervo e duas coordenadoras na Direção, como mostra a Tabela 4 juntamente com algumas características sócio-profissionais.

Tabela 7. Características sócio profissionais.

\begin{tabular}{c|c|c|c|c|c|c|c}
\hline Profissional & Função & Idade & Sexo & Estatura & $\begin{array}{c}\text { Carga horária } \\
\text { semanal }\end{array}$ & $\begin{array}{c}\text { Jornada } \\
\text { diária }\end{array}$ & Turnos \\
\hline $\mathbf{1}$ & $\begin{array}{c}\text { Atendente } \\
\text { Secretaria }\end{array}$ & 54 & Fem. & $1,67 \mathrm{~m}$ & $20 \mathrm{hs}$ & $4 \mathrm{hs}$ & Manhã \\
\hline $\mathbf{2}$ & $\begin{array}{c}\text { Coordenadora } \\
\text { Direção }\end{array}$ & 45 & Fem. & $1,70 \mathrm{~m}$ & $20 \mathrm{hs}$ & $4 \mathrm{hs}$ & Manhã \\
\hline $\mathbf{3}$ & $\begin{array}{c}\text { Coordenadora } \\
\text { Direção }\end{array}$ & 50 & Fem. & $1,58 \mathrm{~m}$ & $35 \mathrm{hs}$ & Até 6 hs & $\begin{array}{c}\text { Manhã e } \\
\text { Tarde }\end{array}$ \\
\hline $\mathbf{4}$ & $\begin{array}{c}\text { Atendente } \\
\text { Secretaria }\end{array}$ & 40 & Fem. & $1,62 \mathrm{~m}$ & $20 \mathrm{hs}$ & $4 \mathrm{hs}$ & Manhã \\
\hline $\mathbf{5}$ & $\begin{array}{c}\text { Atendente } \\
\text { Acervo }\end{array}$ & 68 & Fem. & $1,65 \mathrm{~m}$ & $40 \mathrm{hs}$ & $8 \mathrm{hs}$ & $\begin{array}{c}\text { Manhã e } \\
\text { Tarde }\end{array}$ \\
\hline $\mathbf{6}$ & $\begin{array}{c}\text { Atendente } \\
\text { Acervo }\end{array}$ & 52 & Fem. & $1,58 \mathrm{~m}$ & $20 \mathrm{hs}$ & $4 \mathrm{hs}$ & Manhã \\
\hline $\mathbf{7}$ & Atendente & 68 & Fem. & $1,58 \mathrm{~m}$ & $20 \mathrm{hs}$ & $4 \mathrm{hs}$ & Tarde \\
\hline
\end{tabular}




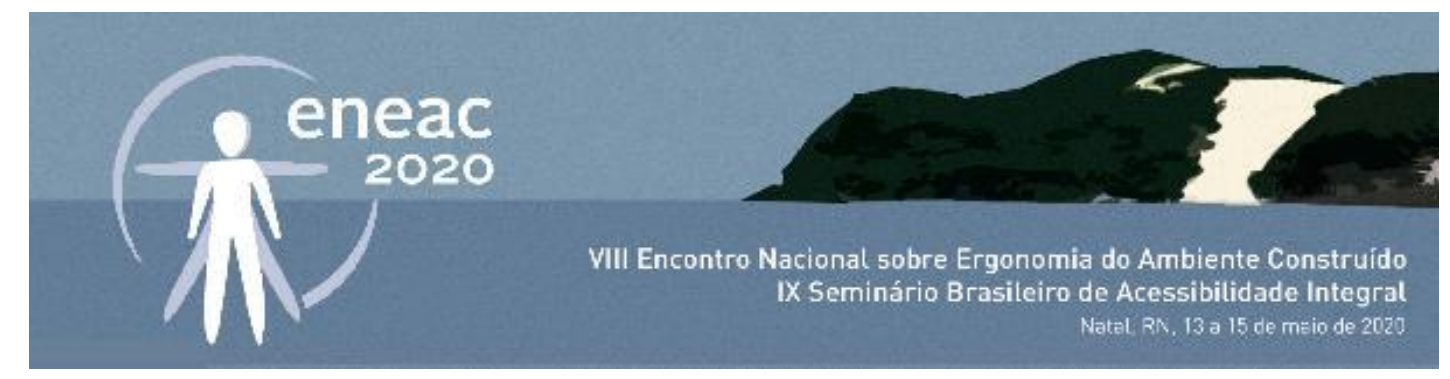

\begin{tabular}{c|c|c|c|c|c|c|c}
\hline & Acervo & & & & & & \\
\hline $\mathbf{8}$ & $\begin{array}{l}\text { Atendente } \\
\text { Secretaria }\end{array}$ & 61 & Fem. $1,72 \mathrm{~m}$ & $20 \mathrm{hs}$ & $4 \mathrm{hs}$ & Tarde \\
\hline
\end{tabular}

Além dos dados apresentados na Tabela 7, foi apurado que, o tempo de trabalho dessas profissionais na biblioteca varia de dois a sete anos e, nesse período, apenas duas relataram afastamento do trabalho por problemas de saúde física advindos de sua atividade laboral, ambas por motivo de doença relacionada à coluna. Ainda, uma das oito funcionárias é portadora de mobilidade reduzida permanente, porém, tal deficiência não está relacionada ao trabalho na biblioteca.

Dentre os principais problemas percebidos em seu ambiente e atividade laboral está o mobiliário existente, que segundo a coordenadora geral, é o mesmo utilizado nas escolas, não sendo ideal para o trabalho em bibliotecas. $O$ espaço físico e os fluxos espaciais também comprometem o trabalho, sendo que, atualmente, o espaço é considerado pequeno para as necessidades, principalmente se tratando das atividades artísticas e culturais realizadas no salão do Acervo. Essas atividades promovem maior fluxo de pessoas tornando o ambiente incompatível com os usuários que necessitam de silêncio para ler ou estudar.

O conforto ambiental é outro fator que interfere nas atividades laborais. O problema percebido quanto ao ruído se refere à proximidade que a edificação tem com a via, havendo muito ruído de construção e circulação de automóveis, já que a porta de acesso à biblioteca necessita ficar constantemente aberta para o público, tornando o ruído advindo do exterior constante e desconfortável. A iluminação também foi percebida negativamente, mas não do ponto de vista do conforto, e sim técnico, sendo descrita como antiquada quanto aos suportes (luminárias) e inadequada quanto à manutenção (reposição de lâmpadas queimadas).

Quanto à ventilação, a reivindicação consiste em uma adequação imediata, pois interfere no conforto térmico das funcionárias. A porta de acesso à biblioteca possui fechamento maciço e precisa ser mantida aberta para os usuários, o que faz como que, no verão, o ar condicionado não se torne eficaz, e no inverno, o frio e a umidade atrapalhem. A solicitação, nesse caso, consiste em trocar a porta maciça por uma envidraçada, o que permitiria a permeabilidade visual e a incidência de luz, sem prejudicar o acesso. Outro fator relatado consiste na inadequada acessibilidade, sendo que, a entrada pelo terreno da biblioteca possui desnível acentuado e piso irregular, sendo impróprio para o acesso de cadeirantes, portadores de mobilidade reduzida e idosos. Além disso, se faz necessário um corrimão desde o acesso pelo portão do terreno até a porta de entrada da biblioteca.

Em relação aos resultados obtidos através da aplicação do questionário, o conforto ambiental corrobora o relato dos problemas percebidos e apontados pela coordenadora geral na entrevista sumariamente realizada, como também, com os resultados da aferição ambiental e das observações direcionadas. O conforto acústico foi avaliado em sua maioria como "Quase 
sempre desconfortável", totalizando 37,5\% (3). O item melhor avaliado foi o conforto lumínico, apontado como "Confortável", com total de $62,5 \%$ (5). Já o item que obteve a pior avaliação foi o conforto térmico, tanto para o verão, com um total de $62,5 \%$ (5), quanto para o inverno, totalizando 75\% (6), ambos percebidos como "Quase sempre desconfortável".

Quanto aos fatores de projeto, as dimensões físicas dos ambientes foram avaliadas em sua maioria como "Regular" para 50\% (4). Quando questionadas sobre as possibilidades de deslocamento pelos ambientes de trabalho, obteve-se uma avaliação positiva, com percentual de $37,5 \%$ (3) para "Bom". Já o conforto do mobiliário obteve a pior avaliação, totalizando $50 \%$ (4) como "Ruim", e a distribuição do mobiliário nos ambientes de trabalho totalizou 75\% (6) como "Regular". A qualidade estética (cores, formas, materiais) presente nos ambientes da biblioteca obteve empate na avaliação das trabalhadoras com 37,5\% (3) para "Bom" e "Regular".

\section{Diagnóstico e recomendações}

A Biblioteca estudada foi projetada com o propósito ao qual se destina. Apesar disso, o espaço existente não se encontra adequado para a realização das atividades, principalmente em função da demanda atual, uma vez que o prédio possui trinta anos e, como o passar do tempo, há o aumento frequente do acervo e, consequentemente, do público frequentador, além das mudanças no formato de oferecer informação e conhecimento associados à cultura e arte. Diante disso, o espaço existente necessita ser revisto e adaptado, tendo por base os resultados dessa pesquisa, a fim de proporcionar maior satisfação às profissionais e demais usuários, uma vez que não há a possibilidade de ampliação das dimensões físicas da edificação da biblioteca.

Nos três ambientes analisados o mobiliário precisa ser substituído para atender aos requisitos mínimos de conforto ergonômico, principalmente quanto às mesas, que possuem quinas e superfícies rígidas, e às cadeiras, que necessitam ter estofamento, regulagem de altura, braços e encosto. $\mathrm{O}$ apoio para os pés durante atividades que exigem longos períodos sentados é imprescindível, além do ajuste de altura dos monitores de computador. As estantes de madeira do acervo também necessitam ser substituídas por estantes de metal, e seria ideal que fossem realocadas em um layout que trouxesse melhorias no fluxo e na distribuição espacial, e ainda, que suas alturas fossem padronizadas. Considera-se urgente a criação de um posto de trabalho específico para a atendente do acervo, com mobiliário adequado e em local funcional e estratégico para as atividades realizadas.

Para o conflito existente na área do acervo em função das atividades artísticas e culturais desenvolvidas no mesmo local, recomenda-se a limitação de dias e horários específicos para cada atividade, necessitando reelaborar o horário de funcionamento da biblioteca como um todo. Outra sugestão consiste em fornecer cabines acústicas de estudo e leitura tanto individuais, como coletivas, ou ainda, um fechamento retrátil que isole os dois ambientes de maneira provisória, mas efetiva.

O balcão de atendimento na secretaria precisa ser redimensionado diminuindo o peitoril para $0,90 \mathrm{~m}$ e aumentando a profundidade para $0,30 \mathrm{~m}$, como também, realocando a mesa da atendente próxima, permitindo assim, maior conforto por parte da funcionária em executar suas atividades, evitando frequentes torções de tronco e elevação de membros superiores, e ainda, garantindo acessibilidade aos usuários cadeirantes. Além disso, o layout dos armários e estantes da secretaria precisa ser revisto, como também, a localização dos equipamentos como impressora e telefone. É imprescindível a instalação de uma extensão telefônica nesse 


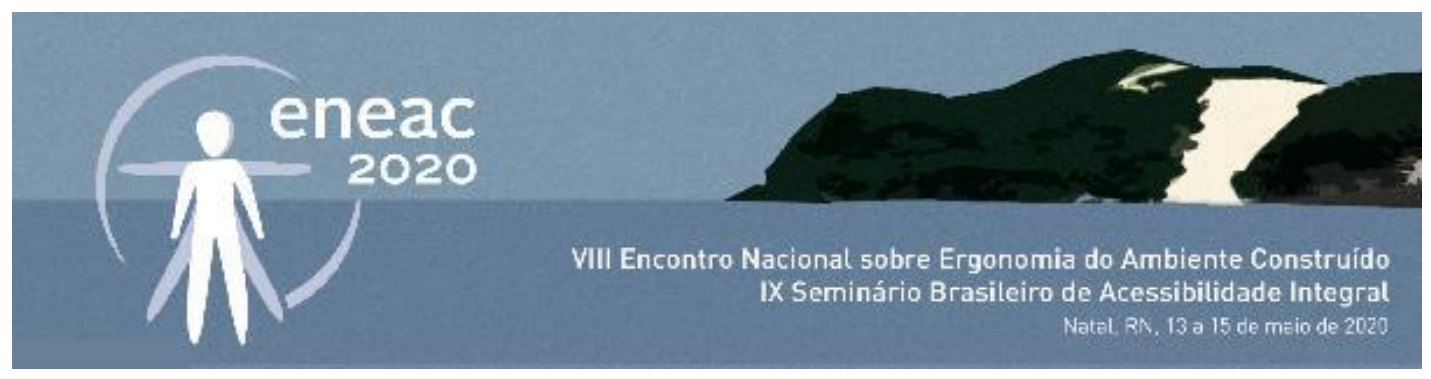

ambiente. Quanto aos itens relacionados ao conforto ambiental, as luminárias precisam ser revistas e as lâmpadas necessitam atenção constante quanto a sua manutenção.

O ruído pode ser minimizado através de um melhor isolamento acústico nas janelas, como por exemplo, a troca de vidros simples por vidros duplos, como também, pela troca da porta maciça da entrada da biblioteca por uma envidraçada. A instalação de ar condicionado com capacidade mínima de 7.0000 BTUs na secretaria e na direção também é necessária para garantir o conforto térmico, tanto no verão, como no inverno. Já no acervo, seriam necessárias mais duas unidades condicionadoras com a mesma capacidade existente (30.000 BTUs) para suprir a demanda conforme as dimensões físicas do ambiente.

\section{Considerações Finais}

O presente artigo ponderou acerca das questões ergonômicas que envolvem uma Biblioteca Pública Municipal, com o intuito de, através de uma abordagem multimétodos, identificar os principais problemas que interferem nas atividades laborais (físicos, ambientais e perceptivos) e, consequentemente, promover melhorias na saúde e bem-estar dos profissionais e em seus ambientes de trabalho. Nessa perspectiva, a pesquisa apresentou alguns fatores utilizados pela ergonomia, dentre os quais a acústica, a iluminação, a temperatura, a umidade, o mobiliário e demais aspectos físicos. Foram apontados parâmetros, como níveis de ruído, iluminamento e temperatura recomendáveis, entre outros, para que a adaptação das condições de trabalho às características e conforto dos trabalhadores seja mais eficiente e produtiva.

Foi possível elaborar adequações necessárias e melhorando as condições físicas de trabalho, de tal maneira a humanizar os ambientes, valorizando esses protagonistas e ao mesmo tempo proporcionando qualidade de vida no trabalho, possibilitando a prestação de um serviço de qualidade aos usuários. Os resultados desse estudo evidenciaram algumas prioridades para a melhoria dos ambientes analisados, como: o controle dos níveis de temperatura através de um sistema de climatização adequado; aumento dos níveis de iluminamento; elaboração de um novo layout espacial com adequação do mobiliário, através de uma avaliação mais detalhada juntamente a arquitetos, engenheiros e bibliotecários, a fim de otimizar os fatores ambientais e físicos; fazer um levantamento de todos os equipamentos existentes para verificar a quantidade, a qualidade, as condições de funcionamento e a adequação às necessidades de trabalho; dar atenção especial às questões relacionadas à acessibilidade.

\section{REFERÊNCIAS}

ASSOCIAÇÃO BRASILEIRA DE NORMAS TÉCNICAS. NBR 10152: Acústica - níveis de pressão sonora em ambientes internos a edificações. 2 ed. Rio de Janeiro, 2017.

BAKER, J.; GREWAL, D.; PARASURAMAN, A.. The Influence of Store Environment on Quality Inferences and Store Image. Journal Of The Academy Of Marketing Science, [s.I.], v. 22, n. 4, p.328-339, 1 set. 1994. Springer Nature. http://dx.doi.org/10.1177/0092070394224002. 
BORTOLIN, S.; CRISPIM JUNIOR, M.; SILVA, R. J. Espaços para a ociosidade na biblioteca. Informação@Profissões, v. 4, n. 1, p. 104-119, 2015. DOI: 10.5433/2317-4390.2015v4n1p104

BRASIL. Ministério da Economia. Secretaria de Trabalho. Portaria MTb no 876, de 24 de outubro de 2018. Norma Regulamentadora № 17 - Ergonomia. Disponível em:

https://enit.trabalho.gov.br/portal/images/Arquivos SST/SST NR/NR-17.pdf. Acesso em: 20 de janeiro de 2019.

FUNDACENTRO. Norma de higiene ocupacional: avaliação dos níveis de iluminamento em ambientes internos de trabalho: procedimento técnico. São Paulo, 2018. Disponível em:

https://drive.google.com/file/d/1b5djDF5elZy7gBHJNsAqSUVwuWxJnROh/view. Acesso em: 19 de setembro de 2018.

HUANG, Li et al. A study on the effects of thermal, luminous, and acoustic environments on indoor environmental comfort in offices. Building And Environment, [s.I.], v. 49, p.304-309, mar. 2012. Elsevier BV.

http://dx.doi.org/10.1016/j.buildenv.2011.07.022.

INSTITUTO NACIONAL DE METEOROLOGIA. Passo Fundo - RS: previsão do tempo. Disponível em:

http://www.inmet.gov.br/portal/index.php?r=tempo2/verProximosDias\&code=431410018. Acesso em: 20 de janeiro de 2019.

INTERNATIONAL ERGONOMICS ASSOCIATION. What is ergonomics? Disponível em: https://www.iea.cc/whats/index.html. Acesso em: 3 de Janeiro de 2019.

INTERNATIONAL ORGANIZATION FOR STANDARDIZATION. ISO 10551:2019. Ergonomics of the physical environment - Subjective judgement scales for assessing physical environments. 2 ed.Genebra, 2019.

MELLO, Paula Maria Abrantes Cotta de et al. (orgs.). Manual de conservação de acervos bibliográficos da UFRJ. Rio de Janeiro : Universidade Federal do Rio de Janeiro. Sistema de Bibliotecas e Informação - UFRJ /SiBI, 2004. Disponível em:

file://C:/Users/grace/AppData/Local/Packages/Microsoft.MicrosoftEdge 8wekyb3d8bbwe/TempState/Downloads/ Manual\%20de\%20Conservacao\%20de\%20Acervos\%20Bibliograficos\%20da\%20UFRJ\%20(1).pdf. Acesso em: 18 de dezembro de 2018.

MIGUEL, Alberto Sérgio S. R. Manual de higiene e segurança no trabalho (13a ed). Portugal: Porto Editora, 2014.

BRASIL. Ministério do Trabalho e Emprego. Manual de aplicação da Norma Regulamentadora no 17 (2a ed). Brasília: TEM, 2002. Disponível em: http://www.ergonomia.ufpr.br/MANUAL_NR_17.pdf. Acesso em: 18 de dezembro de 2018.

MINUZZO, Liziane Ungaretti.. Programa de Necessidades para a Nova Sede da Biblioteca Pública do Estado do Rio Grande do Sul. Em Questão, n. 2, v. 10, p. 389-403, 2004. Disponível em:

http://www.brapci.inf.br/index.php/res/v/11589. Acesso em: 18 de dezembro de 2018.

PREFEITURA MUNICIPAL DE PASSO FUNDO. Biblioteca Pública Municipal Arno Viunisk. Disponível em: http://www.pmpf.rs.gov.br. Acesso em: 18 de dezembro de 2018.

SCOPEL, Vanessa Guerini. Percepção do ambiente e a influência das decisões arquitetônicas em espaços de trabalho. Revista arq.urb, n. 13. Disponível em: https://usjt.br/arq.urb/numero-13/9-vanessa-scopel.pdf. Acesso em: $18 \mathrm{de}$ dezembro de 2018.

SILVA, Andrea Aparecida; LUCAS, Elaine Rosângela de Oliveira. Abordagem ergonômica do ambiente de trabalho na percepção dos trabalhadores: estudo de caso em biblioteca universitária. Revista ACB: Biblioteconomia em Santa Catarina, Florianópolis, v.14, n.2, 382-406, 2009. Disponível em:

file://C:/Users/grace/AppData/Local/Packages/Microsoft.MicrosoftEdge 8wekyb3d8bbwe/TempState/Downloads/5 78-3029-1-PB\%20(1).pdf. Acesso em: 18 de dezembro de 2018.

SISTEMA NACIONAL DE BIBLIOTECAS PÚBLICAS (SNBP). Informações das Bibliotecas Públicas. Disponível em: http://snbp.cultura.gov.br/bibliotecaspublicas/. Acesso em: 4 de janeiro de 2019.

TRINKLEY, Michael. Considerações sobre preservação na construção e reforma de bibliotecas: planejamento para preservação. 2a ed. Rio de Janeiro: Projeto Conservação Preventiva em Bibliotecas e Arquivos, 2001.

ZEISEL, John. Inquiry by design: tools for environment-behaviorn research. New York: Cambridge University Press, 2006. 